\title{
ASSOCIATION BETWEEN IRON AND THYROID STATUS IN PREGNANT WOMEN
}

\author{
Ginka Delcheva $^{1 *}$, Ana Maneva ${ }^{1}$, Tanya Deneva ${ }^{2}$, Anelia Bivolarska $^{1}$ \\ 1) Department of Medical Biochemistry, Faculty of Pharmacy, Medical Univer- \\ sity of Plovdiv, Bulgaria \\ 2) Department of Clinical Laboratory, Faculty of Pharmacy, Medical Univer- \\ sity of Plovdiv, Bulgaria.
}

\section{ABSTRACT}

Purpose: Pregnancy is often complicated by iron deficiency, affecting negatively thyroid gland physiology. The aim of our study is to investigate parameters of iron and thyroid status during I, II and III trimester of pregnancy in order to establish potential correlations in their dynamics.

Materials and methods: The study involved 61 pregnant women and 43 controls. Their iron and thyroid status was determined by measuring hemoglobin ( $\mathrm{Hb})$, serum ferritin $(\mathrm{SF})$, serum transferrin receptor (sTfR), thyroxine (FT4) and thyroid-stimulating hormone (TSH).

Results: Significant differences between pregnant women and the control group were found, indicating an iron deficiency risk: sTfR level was higher, while $\mathrm{Hb}$, ferritin and FT4 levels were lower in pregnant women. Thyroxine correlated positively with $\mathrm{Hb}(\mathrm{p}=0.016)$ and ferritin $(\mathrm{p}=0.003)$ in pregnant women. In the I trimester, there was a negative association between STfR and FT4 $(p=0.013)$, and in the III trimester, there was a positive association between sTfR and TSH ( $<<0.0001)$.

Conclusions: sTfR represented the relationship between iron and thyroid status in the I and III trimester. Iron deficiency was expressed in the III trimester with a positive association between sTfR and TSH. The increased maternal iron requirement (sTfR) correlated with increased TSH secretion induced by decreased thyroxine.

Keywords: iron deficiency, pregnant women, ferritin, sTfR, thyroxine, TSH,

\section{INTRODUCTION}

The mechanism relating iron homeostasis with thyroid status still remains unclear. It has been previously reported that iron deficiency may affect thyroid function $[1,2]$. Iron deficiency in rat embryos and neonatal rats reduces thyroid hormone-responsive gene mRNA levels in the hippocampus and cerebral cortex [3]. On the other hand, there is experimental evidence revealing the effect of thyroid hormones on ferritin expression. High levels of triiodothyronine (T3) are related to increased expression of ferritin in K562 cells but do not affect the expression of the transferrin receptor [4]. The administration of $\mathrm{T} 3$ in hypothyroid individuals causes a significant in- crease in the level of serum ferritin [5] and is explained as a positive correlation of thyroid hormones with serum ferritin [6].

The first step of thyroid hormones synthesis is iodine oxidation catalyzed by the iron-containing enzyme thyreoperoxidase (TPO), which is activated by TSH. Iron deficiency can impair TPO activity and thyroid metabolism and may cause decreased production of thyroid hormones [7-9]. Additional administration of iron improves the efficacy of the iodine-enriched salt in goitrous and iron-deficient children $[10,11]$, which is essential in the treatment of children with often overlapping deficiencies [12]. Some studies report that iron supplementation in hypothyroidism also requires additional administration of thyroxine to correct the thyroid hypofunction [13]. Researches on patients with iron deficiency anemia and subclinical hypothyroidism reveal that oral administration of ferrous iron salts alone is not sufficient to restore normal functions of the thyroid gland and only a combined treatment of levothyroxine and iron salts has a therapeutic effect $[14,15]$.

Iron deficiency is often observed in pregnant women, and it has negative effects on thyroid gland metabolism [16]. Impaired function of the maternal thyroid gland during pregnancy may cause retardation in the development of the neonatal nervous system. In a comprehensive clinical study during the third trimester of pregnancy, Zimmermann et al. have found that the parameters for evaluation of iron homeostasis - serum ferritin, transferrin receptor and body iron stores predict changes in thyroid status [17].

The aim of our study is to investigate the parameters of iron homeostasis (Hb, SF and sTfR) and thyroid status (FT4 and TSH) during I, II and III trimester of pregnancy in order to establish the associations in their dynamics and to define the most sensitive marker for detection of iron deficiency and thyroid dysfunction during the different trimesters of pregnancy.

\section{MATERIALS AND METHODS}

The iron and thyroid status in healthy pregnant women and clinically healthy women was determined by measuring $\mathrm{Hb}, \mathrm{SF}$ and sTfR, FT4 and TSH. The research was approved by the Ethics Committee at Medical University of Plovdiv (protocol No.4/18.07.2013) according 
to the Declaration of Helsinki. Voluntary participation of the human subjects was documented with signed informed consent. The study involved 61 healthy pregnant women admitted to the department of Obstetrics and Gynaecology, MPHAT - Asenovgrad, Bulgaria. The mean age of pregnant women was $27.6 \pm 4.6$ years compared to 43 clinically healthy women as a control group with the mean age of $28.8 \pm 5.2$ years.

Blood was collected in monovettes via venipuncture. The blood samples were immediately centrifuged at $1000 \times \mathrm{g}$ for $15 \mathrm{~min}$ at $4^{\circ} \mathrm{C}$ and stored at $-20^{\circ} \mathrm{C}$ prior analysis. Thyroxine and TSH levels in human sera were determined with commercial ELISA kits (Globe Diagnostics, Milan, Italy), following the manufacturer's protocol. $\mathrm{Hb}$ levels in blood were measured on hematology analyzer STKS Coulter, USA and Sysmex 9500, Kobe, Japan. ELISA was used to determine serum ferritin and sTfR levels with commercially available kits (BioVendor, Brno, Czech Republic) according to the manufacturer's instructions. Serum levels of C-reactive protein (CRP) were measured by an immunturbidimetric, endpoint method via automated analysis (Konelab 60i, Thermo Scientific, Finland) and samples with CRP > $10 \mathrm{mg} / \mathrm{L}$ were omitted.

Statistical software package SPSS 17.0 for Windows (SPSS Inc.) was used. Results are given as Mean \pm standard deviation (SD) or as Median (95\% CI). Quantitative variables were tested for normality of data distribution using Kolmogorov-Smirnov test (One-Sample KolmogorovSmirnov D-Test) and Shapiro-Wilk's tests. The difference between means of two independent groups with Gaussian distribution was evaluated with Student t-test, and for comparison of non-Gaussian distributed variables, MannWhitney U test was used. Pearson and Spearman correla- tion analysis was used depending on the distribution of the parameters. Statistical significance was defined as $p$ $<0.05$.

\section{RESULTS}

\section{Parameters of iron homeostasis}

According to the WHO guidelines, the lower threshold value for $\mathrm{Hb}$ in pregnancy is $110 \mathrm{~g} / \mathrm{L} \mathrm{[18].} \mathrm{The}$ mean of $\mathrm{Hb}$ in the control group was significantly higher in comparison to pregnant women: $131.58 \pm 5.38 \mathrm{~g} / \mathrm{L}(\mathrm{n}$ $=43)$ and $114.64 \pm 11.21 \mathrm{~g} / \mathrm{L}(\mathrm{n}=61),(\mathrm{p}<0.0001)$. In $26 \%$ of pregnant women $(\mathrm{n}=16) \mathrm{Hb}$ level was below $110 \mathrm{~g} / \mathrm{L}$, which indicated iron deficiency during pregnancy. In pregnant women, a significant decrease of serum ferritin was observed - 95\% CI 12.84-20.1 $\mu \mathrm{g} / \mathrm{L}$, compared to the control group - 95\% CI 29.17-53.07 $\mu \mathrm{g} / \mathrm{L}(\mathrm{p}=0.001)$. In $65.6 \%$ of pregnant women $(\mathrm{n}=40) \mathrm{SF}$ was below $15 \mu \mathrm{g} /$ L, which was indicative of an iron deficiency during pregnancy. Compared to the control group, the levels of sTfR were significantly higher. The median of pregnant women group was $1.44 \mu \mathrm{g} / \mathrm{mL}$ (95\% CI 1.48-2.03) and the median of the control group was $0.68 \mu \mathrm{g} / \mathrm{mL}$ (95\% CI $0.66-$ $0.89),(\mathrm{p}<0.0001)$. Almost in half of the pregnant women $(49.2 \%, \mathrm{n}=30) \mathrm{sTfR}$ was above $2.9 \mu \mathrm{g} / \mathrm{mL}$ that was the upper limit according to the manufacturer.

The levels of $\mathrm{Hb}$ and serum ferritin were decreased after the first trimester of pregnancy, while sTfR levels increased with pregnancy progression. Statistically significant differences in serum ferritin and sTfR were found comparing the first trimester with the second and the third one. The levels of sTfR were significantly higher in the third trimester of pregnancy compared to the first trimester (table 1).

Table 1. Comparison of iron homeostasis parameters in trimesters

\begin{tabular}{lccc}
\hline Trimesters & $\mathrm{Hb}^{\mathrm{c}} \mathrm{g} / \mathrm{L}$ & $\mathrm{SF}^{\mathrm{b}} \mathrm{g} / \mathrm{L}$ & $\mathrm{sTfR}^{\mathrm{b}} \mu \mathrm{g} / \mathrm{mL}$ \\
\hline $\mathrm{I}(\mathrm{n}=9)$ & $120.78 \pm 9.08$ & $24.93(18.34-55.06)$ & $0.77(1.09-1.62)$ \\
$\mathrm{II}(\mathrm{n}=19)$ & $117.89 \pm 12.77$ & $13.73(11.85-22.29)$ & $1.21(1.19-2.01)$ \\
& $\mathrm{p}=0.507$ & $\mathrm{p}=0.032^{\mathrm{a}}$ & $\mathrm{p}=0.068$ \\
\hline $\mathrm{I}(\mathrm{n}=9)$ & $120.78 \pm 9.08$ & $24.93(18.34-55.06)$ & $0.77(1.09-1.62)$ \\
$\mathrm{III}(\mathrm{n}=33)$ & $114.64 \pm 9.68$ & $9.38(9.12-12.12)$ & $2.17(1.81-2.35)$ \\
& $\mathrm{p}=0.019^{\mathrm{a}}$ & $\mathrm{p}=0.0001^{\mathrm{a}}$ & $\mathrm{p}=0.008^{\mathrm{a}}$ \\
\hline II $(\mathrm{n}=19)$ & $117.89 \pm 12.77$ & $13.73(11.85-22.29)$ & $1.21(1.19-2.01)$ \\
III $(\mathrm{n}=33)$ & $114.64 \pm 9.68$ & $9.38(9.12-12.12)$ & $2.17(1.81-2.35)$ \\
& $\mathrm{p}=0.031^{\mathrm{a}}$ & $\mathrm{p}=0.04^{\mathrm{a}}$ & $\mathrm{p}=0.076$ \\
\hline
\end{tabular}

a statistical significance

b SF and sTfR have non-Gaussian distribution, the evaluation was based on the median value of the parameters, Median (95\% CI) - Mann-Whitney U Test

${ }^{\mathrm{c}}$ Mean \pm SD - Independent Samples t-test

The distribution of pregnant women (\%) in trimesters is shown in fig. 1 . The subjects were divided into two groups according to the level of $\mathrm{Hb}$, SF and sTfR. The first group corresponds to an iron deficiency condition, and the second to normal iron homeostasis. The results indicate an increase in iron deficiency with the progression of pregnancy. 
Fig. 1. Distribution of pregnant women (\%) in trimesters according to the levels of: a. $\mathrm{Hb}<110 \mathrm{~g} / \mathrm{L}$ and $>110 \mathrm{~g} /$ L; b. $\mathrm{SF}<15 \mathrm{ng} / \mathrm{mL}$ and $>15 \mathrm{ng} / \mathrm{mL}$; c. $\mathrm{sTfR}>2.9 \mu \mathrm{g} / \mathrm{mL}$ and $<2.9 \mu \mathrm{g} / \mathrm{mL}$
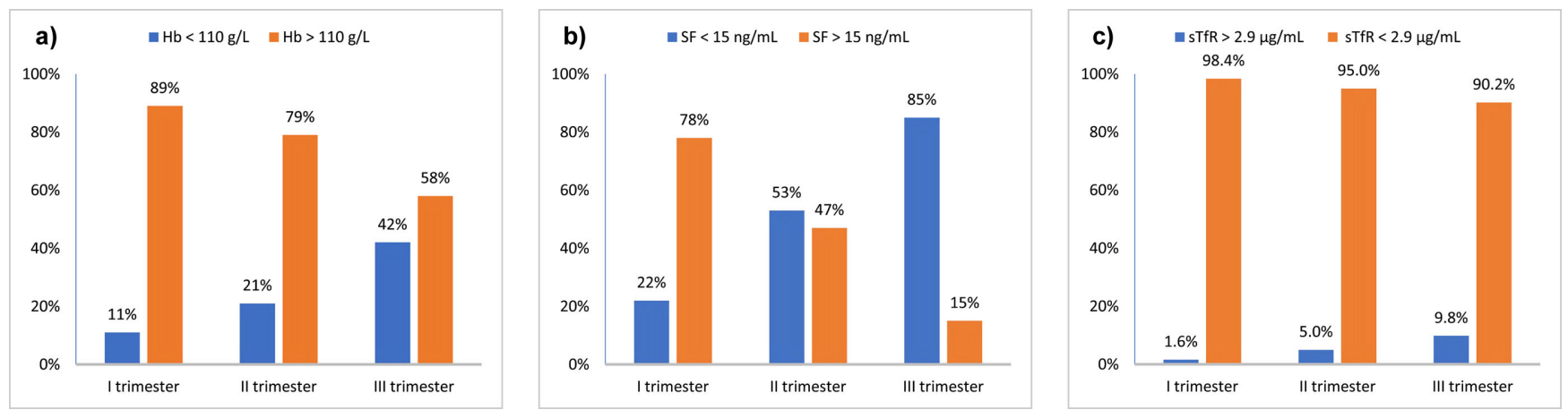

In the group with pregnant women, there was a sig- not observed in the control group. A statistically signifinificant negative correlation between STfR and SF and cant correlation between SF and Hb was not found in between sTfR and $\mathrm{Hb}$ (fig. 2). These associations were both groups.

Fig. 2. Correlations between iron homeostasis parameters in pregnant women and control group (a, b, c, d)

a)

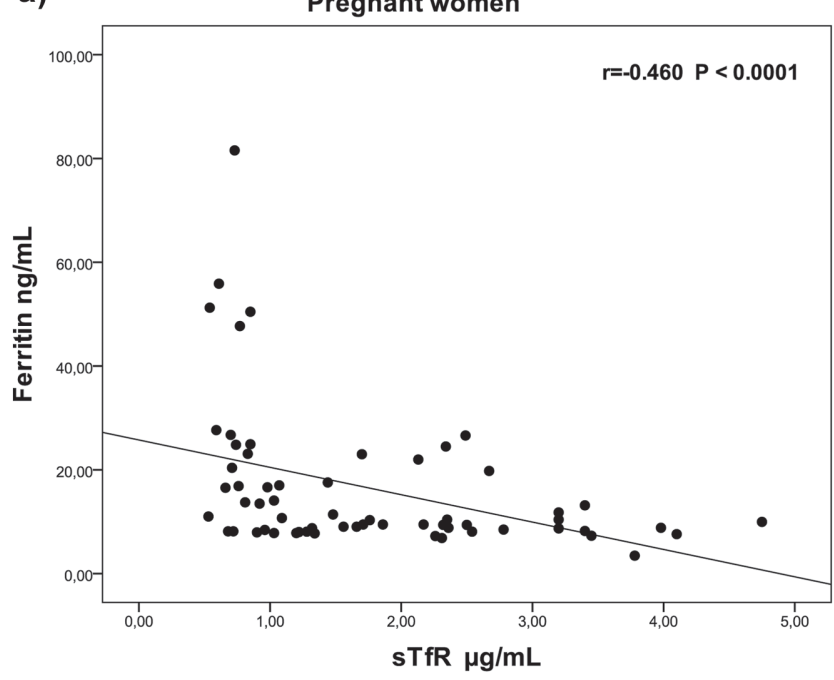

c)

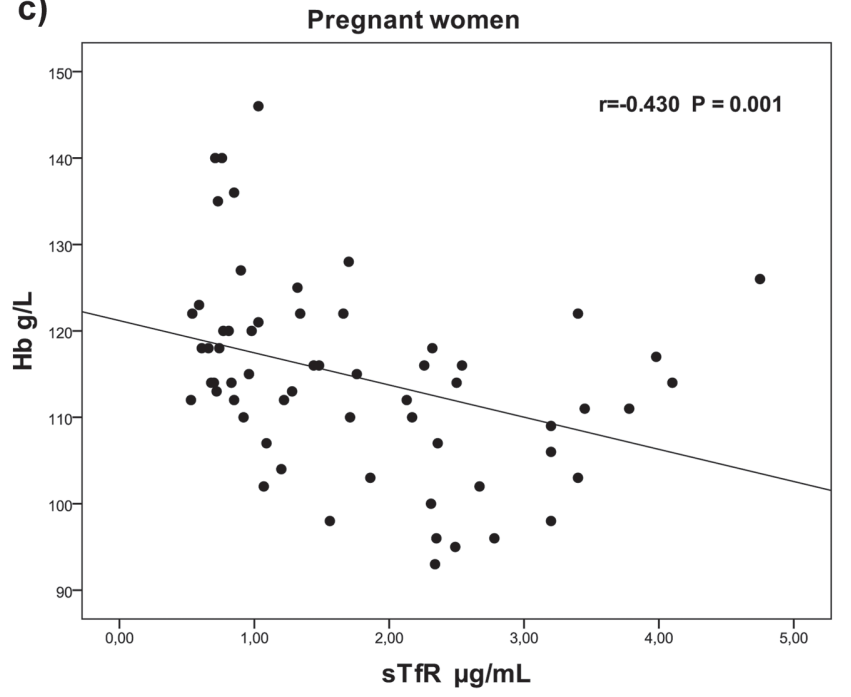

Parameters of thyroid status

The level of free thyroxine in the control group was significantly higher compared to pregnant women: mean

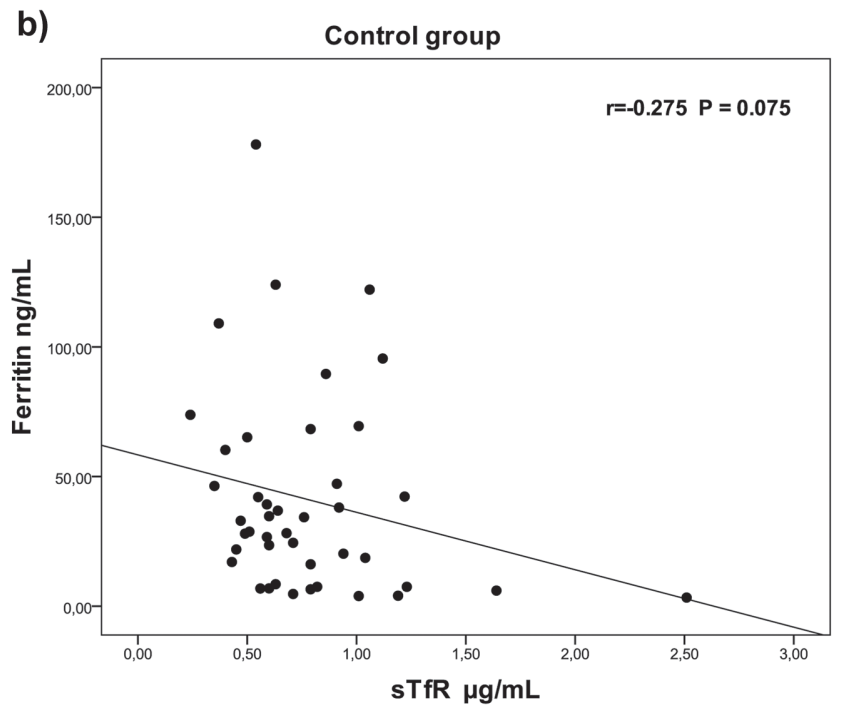

d)

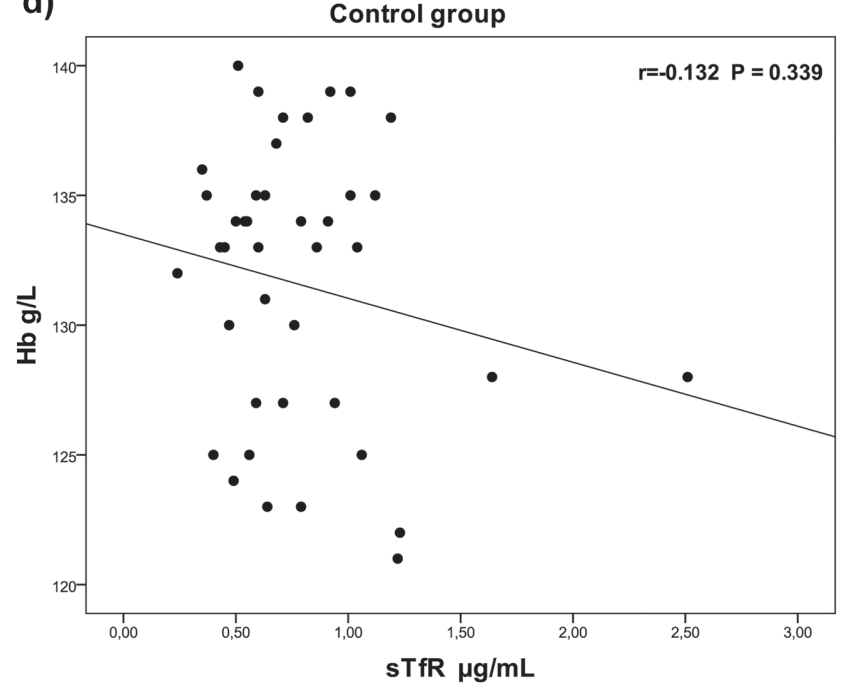

FT4 in pregnant women was $9.27 \pm 1.79 \mathrm{pmol} / \mathrm{L}$, and in the control group, it was $13.83 \pm 2.26 \mathrm{pmol} / \mathrm{L}(\mathrm{p}<0.0001)$. TSH level was lower in the control group compared to pregnant 
women: median TSH in pregnant women was $1.47 \mathrm{mIU} / \mathrm{L}$ (95\% CI 1.59-2.25), and in the control group, it was 1.15 $\mathrm{mIU} / \mathrm{L}$ (95\% CI 1.18-1.74). The difference was not statistically significant, $p=0.141$. The levels of FT4 and TSH were higher in the early months of pregnancy and decreased gradually, but a statistically significant difference in the concentration of the hormones in the different trimesters was not found. The results on thyroxine levels show that the women in the I trimester had mean FT4 $9.89 \pm 0.91 \mathrm{pmol} / \mathrm{L}$, in the II trimester $8.88 \pm 0.41 \mathrm{pmol} / \mathrm{L}$, in the III trimester $9.33 \pm$ $0.26 \mathrm{pmol} / \mathrm{L}$, and the difference in the hormone levels was not statistically significant. In $22.9 \%$ of pregnant women (n $=14$ ), FT4 was below the lower limit, 3 of the subjects were in the I trimester, 4 in the II trimester and 7 in the III trimes- ter. The women with normal FT4 level were 6 in the I semester, 15 in the II and 26 in the III trimester. According to Zimmerman et al. [17], TSH above $4 \mathrm{mIU} / \mathrm{L}$ indicates mild subclinical hypothyroidism. Median TSH in trimesters was as follows: I trimester 2.39 (95\% CI 0.26-1.98), II trimester 1.28 (95\% CI 1.08-2.15) and III trimester 1.58 (95\% CI 1.67$2.36)$. In the entire group, $11.5 \%$ of women $(n=7)$ had TSH above $4 \mathrm{mIU} / \mathrm{L}$. Six of the subjects were in the third trimester, and one was in the first trimester. TSH in trimesters was expressed as Median. The distribution of pregnant women $(\%)$ in trimesters according to the FT4 level $<9 \mathrm{pmol} / \mathrm{L}$ and $>9 \mathrm{pmol} / \mathrm{L}$ is shown in Fig. 3a, and according to TSH level $<1.47 \mathrm{mIU} / \mathrm{L}$ and $>1.47 \mathrm{mIU} / \mathrm{L}$ is shown in fig. $3 \mathrm{~b}$.

Fig. 3. Distribution of pregnant women $(\%)$ in trimesters according to the level of: a. FT $4<9$ pmol/L and $>9$ $\mathrm{pmol} / \mathrm{L} ;$ b. TSH $<1.47 \mathrm{mIU} / \mathrm{L}$ and $>1.47 \mathrm{mIU} / \mathrm{L}$
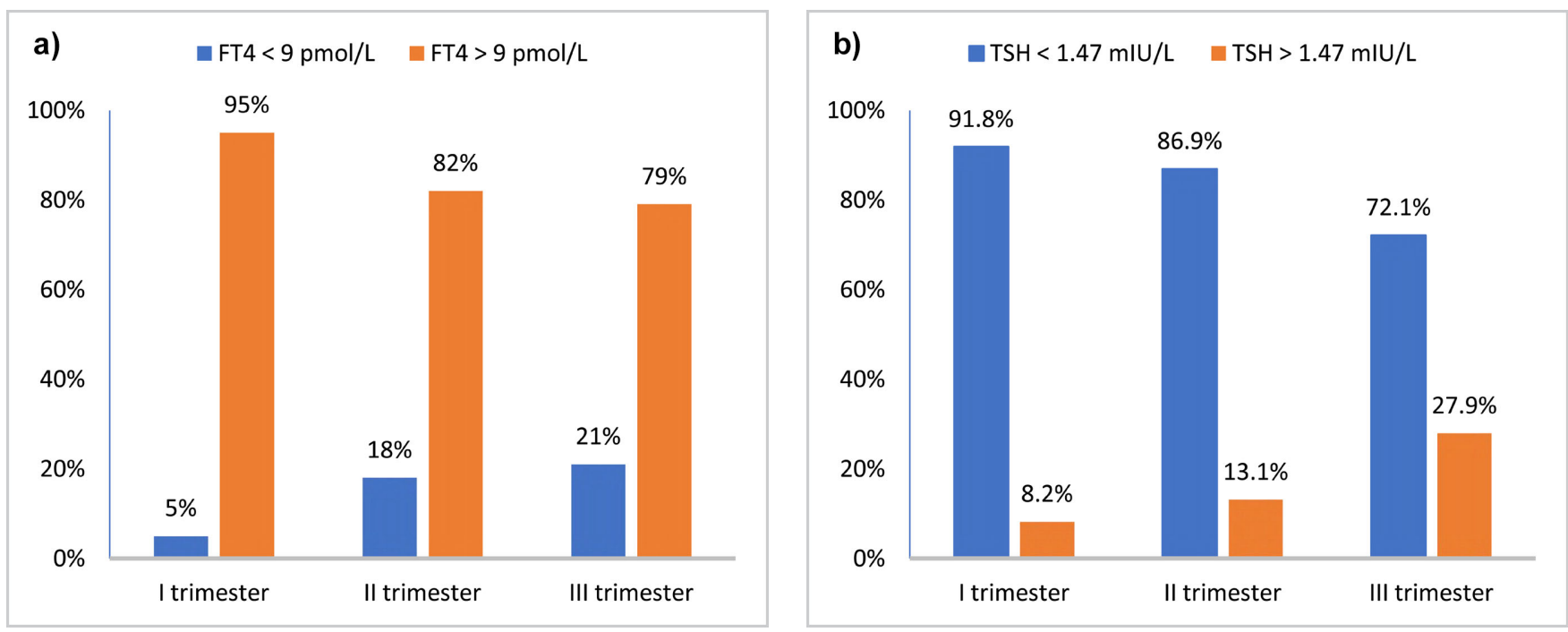

Correlations between iron homeostasis parameters and thyroid status

A significant positive correlation between $\mathrm{Hb}$ level and FT4 and also between SF and thyroxine was found in pregnant women. In the control group, these associations were not observed (fig. 4). No significant correlation between sTfR and thyroxine was found in the target groups - pregnant women and the control group.

Fig. 4. Correlations between $\mathrm{Hb}$, ferritin and FT4 in pregnant women and control group (a, b, c, d)

a)

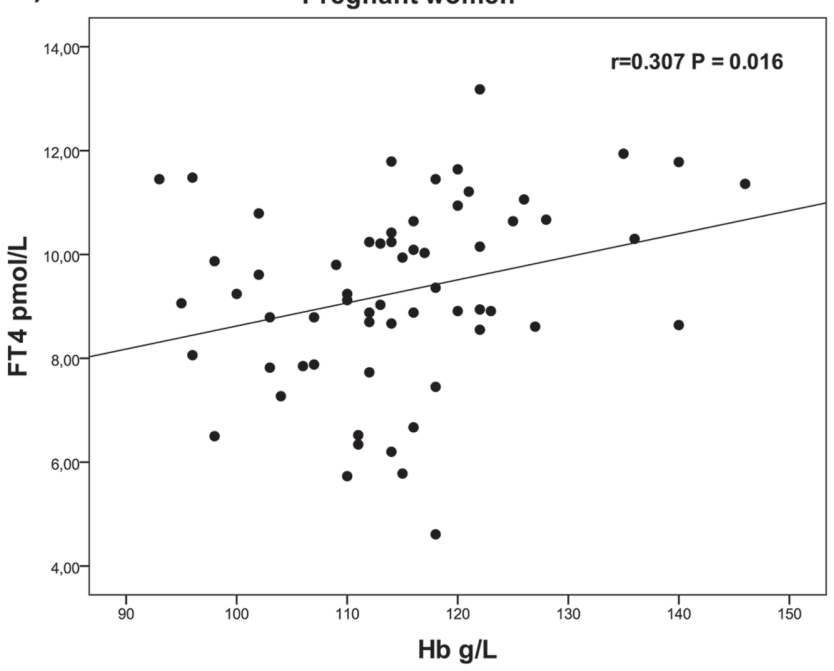

b)

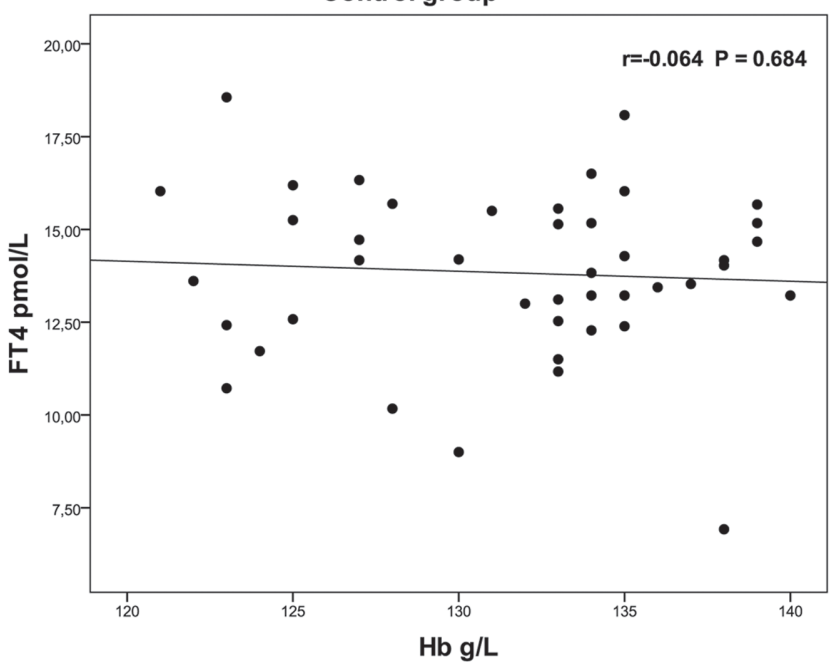


c)

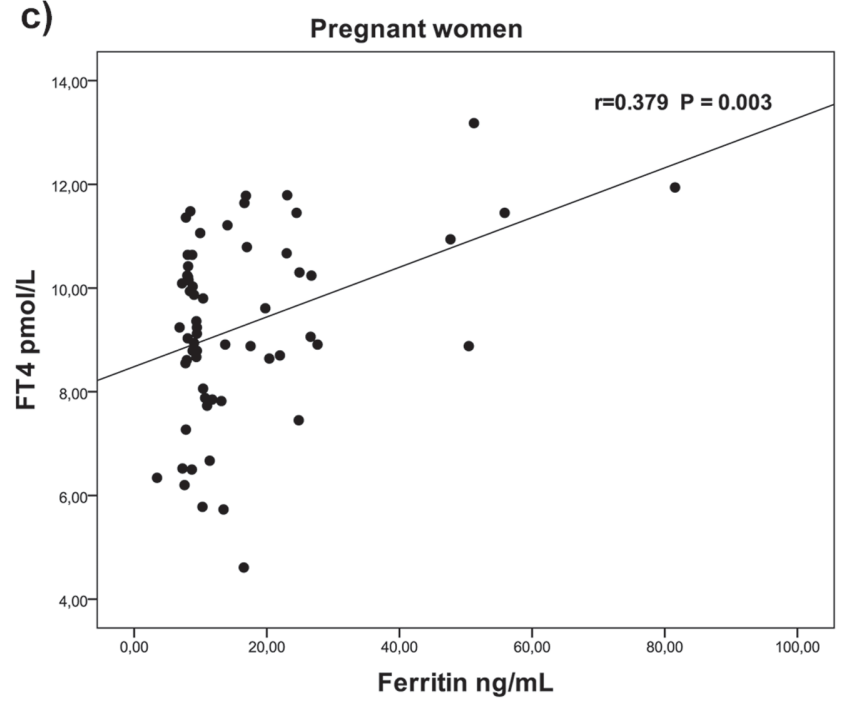

In the first trimester of pregnancy, a strong negative correlation between thyroxine and STfR and a positive correlation between thyroxine and serum ferritin were observed (table 2). During the second trimester, there was a trend for a positive correlation between FT4 and $\mathrm{Hb}$ and for a negative correlation between $\mathrm{TSH}$ and $\mathrm{Hb}$ that also suggested a d)

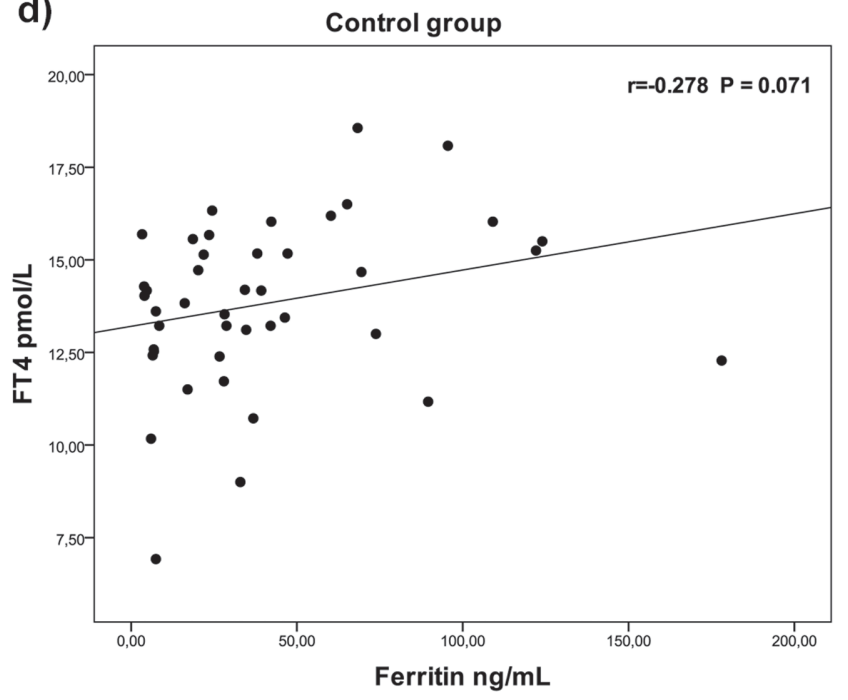

dependence of thyroxine levels on iron supply (table 2). During the third trimester, strong positive correlations between TSH and sTfR and FT4 and SF were observed. They indicated a parallel increase of sTfR together with TSH secretion, induced by decreased thyroxine concentration (table 2).

Table 2. Correlations between parameters of thyroid and iron status in trimesters

\begin{tabular}{lcccccc}
\hline & \multicolumn{2}{c}{ I trimester } & \multicolumn{2}{c}{ II trimester } & \multicolumn{2}{c}{ III trimester } \\
& $\mathrm{r}$ & $\mathrm{p}$ & $\mathrm{r}$ & $\mathrm{p}$ & $\mathrm{r}$ & $\mathrm{p}$ \\
\hline TSH/sTfR & 0.360 & 0.342 & 0.107 & 0.663 & 0.597 & $<0.0001^{\mathrm{a}}$ \\
FT4/sTfR & -0.783 & $0.013^{\mathrm{a}}$ & 0.171 & 0.483 & -0.279 & 0.115 \\
FT4/Hb & 0.496 & 0.174 & 0.397 & 0.092 & -0.004 & 0.980 \\
TSH/Hb & 0.067 & 0.864 & -0.408 & 0.083 & -0.024 & 0.895 \\
TSH/SF & -0.217 & 0.576 & 0.369 & 0.120 & -0.279 & 0.116 \\
FT4/SF & 0.738 & $0.023^{\mathrm{a}}$ & 0.037 & 0.880 & 0.432 & $0.012^{\mathrm{a}}$ \\
\hline
\end{tabular}

${ }^{\text {a }}$ statistical significance

Table 3 presents the number of pregnant women with eters of iron and thyroid status and their correlations in the normal and deviating from the normal values of the paramtwo groups.

Table 3. Correlations between thyroid status hormones and iron homeostasis parameters at normal and deviating values

\begin{tabular}{|c|c|c|c|c|}
\hline & \multicolumn{2}{|c|}{ with low $S F(\mathrm{n}=40)$} & \multicolumn{2}{|c|}{ with normal $S F(\mathrm{n}=21)$} \\
\hline & $\mathrm{r}$ & $\mathrm{p}$ & $\mathrm{r}$ & $\mathrm{p}$ \\
\hline TSH/sTfR & 0.554 & $<0.0001^{\mathrm{a}}$ & -0.093 & 0.688 \\
\hline $\mathrm{TSH} / \mathrm{Hb}$ & -0.358 & $0.023^{\mathrm{a}}$ & 0.064 & 0.782 \\
\hline \multirow[t]{3}{*}{ FT4/Hb } & 0.339 & $0.033^{\mathrm{a}}$ & 0.181 & 0.431 \\
\hline & \multicolumn{2}{|c|}{ with low $H b(\mathrm{n}=19)$} & \multicolumn{2}{|c|}{ with normal $\mathrm{Hb}(\mathrm{n}=42)$} \\
\hline & $\mathrm{r}$ & $\mathrm{p}$ & $\mathrm{r}$ & $\mathrm{p}$ \\
\hline TSH/sTfR & 0.614 & $0.011^{\mathrm{a}}$ & 0.273 & 0.069 \\
\hline FT4/sTfR & -0.198 & 0.463 & -0.208 & 0.170 \\
\hline $\mathrm{FT} 4 / \mathrm{Hb}$ & -0.375 & 0.152 & 0.410 & $0.005^{\mathrm{a}}$ \\
\hline FT4/SF & 0.379 & 0.148 & 0.379 & $0.010^{\mathrm{a}}$ \\
\hline
\end{tabular}




\begin{tabular}{|c|c|c|c|c|}
\hline & \multicolumn{2}{|c|}{ with high $\operatorname{sTfR}(\mathrm{n}=10)$} & \multicolumn{2}{|c|}{ with normal sTfR $(\mathrm{n}=51)$} \\
\hline & $\mathrm{r}$ & $\mathrm{p}$ & $\mathrm{r}$ & $\mathrm{p}$ \\
\hline FT4/Hb & 0.652 & $0.041^{\mathrm{a}}$ & 0.205 & 0.148 \\
\hline \multirow[t]{3}{*}{ FT4/SF } & 0.381 & 0.277 & 0.361 & $0.009^{\mathrm{a}}$ \\
\hline & \multicolumn{2}{|c|}{ with high TSH $(\mathrm{n}=27)$} & \multicolumn{2}{|c|}{ with normal TSH $(\mathrm{n}=34)$} \\
\hline & $\mathrm{r}$ & $\mathrm{p}$ & $\mathrm{r}$ & $\mathrm{p}$ \\
\hline TSH/sTfR & 0.736 & $0.050^{\mathrm{a}}$ & 0.169 & 0.221 \\
\hline $\mathrm{FT} 4 / \mathrm{Hb}$ & 0.021 & 0.965 & 0.320 & $0.018^{\mathrm{a}}$ \\
\hline \multirow[t]{3}{*}{ FT4/SF } & 0.391 & 0.386 & 0.383 & $0.004^{\mathrm{a}}$ \\
\hline & \multicolumn{2}{|c|}{ with low FT4 $(\mathrm{n}=27)$} & \multicolumn{2}{|c|}{ with normal FT4 $(\mathrm{n}=34)$} \\
\hline & $\mathrm{r}$ & $\mathrm{p}$ & $\mathrm{r}$ & $\mathrm{p}$ \\
\hline TSH/sTfR & 0.332 & 0.091 & 0.382 & $0.026^{\mathrm{a}}$ \\
\hline FT4/sTfR & -0.222 & 0.265 & -0.446 & $0.008^{\mathrm{a}}$ \\
\hline $\mathrm{FT} 4 / \mathrm{Hb}$ & 0.273 & 0.168 & 0.485 & $0.004^{\mathrm{a}}$ \\
\hline FT4/SF & 0.316 & 0.108 & 0.416 & $0.014^{\mathrm{a}}$ \\
\hline
\end{tabular}

${ }^{\text {a }}$ statistical significance

The results indicate that in deficiency of SF and $\mathrm{Hb}$, there was a significant positive correlation between TSH and STfR that was also observed in the group with high TSH (table 3). In pregnant women with Hb deficiency, there was a positive correlation only between TSH and STfR and associations between FT4 and iron homeostasis parameters were not observed (table 3 ). In pregnant women with high sTfR, there was a positive correlation only between FT4 and $\mathrm{Hb}$. In pregnant women with normal sTfR levels, there was a positive correlation between FT4 and SF (table 3). In pregnant women with high $\mathrm{TSH}$, there was a significant positive correlation between TSH and sTfR, while in the group with normal $\mathrm{TSH}$, there was a positive correlation between FT4 and Hb and between FT4 and SF (table 3). Only in pregnant women with normal FT4, there were significant correlations between FT4 and iron homeostasis parameters; in the same group, a significant positive correlation between TSH and sTfR was observed (table 3).

\section{DISCUSSION}

Our previous studies report iodine and iron deficiency during pregnancy $[19,20]$. The present research involves pregnant women from risk groups living in iodine deficient regions compared to healthy controls at the same age. Pregnant women were distributed in two subgroups with normal and deviating values of iron homeostasis parameters, FT4 and TSH and the variations of these parameters in trimesters were investigated in order to assess iron deficiency and changes in thyroid status. The correlations of iron homeostasis parameters with FT4 and TSH were also determined.

The results showed significant statistical differences between pregnant women and the control group that indicate an iron deficiency risk: sTfR level was significantly higher, while $\mathrm{Hb}$ and ferritin levels were significantly lower in pregnant women. This finding is in agreement with previous studies on iron deficiency during pregnancy [21, 22]. A significant difference was also observed in thyroxine level but not in the TSH level.

In pregnant women, there were significant negative correlations between sTfR and serum ferritin and also be- tween sTfR and $\mathrm{Hb}$ (fig. 2). These associations were not statistically significant in the control group. We found that all parameters of iron homeostasis were significantly different from the normal levels in the third trimester of pregnancy compared to the first one (table 1, fig. 1 and fig. 3 ). These results indicate the increased iron requirements related to fetal nutrition and growth and a trend for an iron deficiency that was most prominent during the last trimester of pregnancy. In pregnant women, a significant positive association between $\mathrm{Hb}$ and thyroxine and between SF and FT4 was found, which was not observed in the control group (fig. 4). The parallel change of FT4 in relation to SF and $\mathrm{Hb}$ confirms the association between thyroid status and iron stores and the dependence of thyroxine synthesis on iron supply. This finding is in agreement with Gur et al., who report that $\mathrm{Hb}$ correlated positively with FT4 in pregnant women with and without hypothyroidism [23].

In order to explain better the relationship between iron metabolism and thyroid status, the group with pregnant women was separated into subgroups according to the level of SF, Hb, sTfR, TSH and FT4. In pregnant women with low $\mathrm{Hb}$ level, there was a positive correlation between sTfR and TSH (table 3), which suggested a parallel control in the regulation of tissue iron supply and thyroid hormones synthesis. Tong et al. [27] have found that the elevation of sTfR and its negative association with the severity of congenital hypothyroidism suggested the presence of a self-regulating mechanism. In pregnant women with normal FT4, we found that there was a positive correlation between TSH and sTfR, regardless of thyroxine concentration, that indicated a permanent mechanism responsible for the correspondence between iron supply and thyroid hormones synthesis (table 3 ).

Serum ferritin is a parameter for the amount of iron stores, but its increased level is also a factor of inflammation. Therefore, pregnant women with higher than normal levels of SF were excluded. Serum ferritin levels were decreased after the first trimester of pregnancy, while sTfR levels were increased, which was indicative of a progressive decrease of iron stores during pregnancy. sTfR was a more sensitive marker for the increased iron requirement 
than $\mathrm{Hb}$ since there was a significant correlation between SF and sTfR ( $\mathrm{p}<0.0001)$ and between Hb and sTfR ( $\mathrm{p}=$ 0.001 ), and no significant association between SF and $\mathrm{Hb}$ was found (fig. 2). In pregnant women with ferritin levels lower than normal, a positive correlation between STfR and TSH was observed (table 3 ). This suggests an adaptive mechanism stimulating parallel iron uptake and thyroxine synthesis.

The distribution of pregnant women according to TSH and thyroxine level confirmed the correlations observed between the parameters of iron homeostasis and thyroid status. TSH levels were related to the parameters of iron metabolism in order to respond to the intensity of thyroid hormones production: normal TSH values corresponded to a positive correlation between thyroxine and ferritin and also between thyroxine and $\mathrm{Hb}$. The increased values of TSH correlated only with sTfR, and therefore the combined determination of the two parameters would be more informative for the detection of the risk of hypothyroidism and iron deficiency (table 3 ). In pregnant women with low $\mathrm{Hb}$ and $\mathrm{SF}$ and high $\mathrm{TSH}$, there was a positive correlation between TSH and STfR, indicating an adaptive mechanism for simultaneous compensation of iron and thyroxine deficiency (table 3 ). This correlation (TSH/sTfR) was significant in the last trimester of pregnancy $(\mathrm{p}<0.0001)$ (table 2).

The results presented in Table 3 showed that only in pregnant women with ferritin deficiency, which indicates decreased iron stores, there was a negative correlation between TSH (stimulus for FT4 production) and $\mathrm{Hb}$ (reflected hematopoiesis abilities). The positive correlation between iron homeostasis parameters (Hb and SF) and FT4 was not preserved in pregnant women with low $\mathrm{Hb}$. The results suggest disorders in the regulatory mechanisms associated with iron supply and thyroid hormones synthesis (table 3).

The studies regarding the relationship between parameters of iron homeostasis and thyroid status in the different trimesters of pregnancy are rather scarce. Our findings indicate that in the first trimester when maternal stores are not depleted, there is a strong negative correlation between STfR and thyroxine levels that proves the association between iron and thyroid status in pregnant women. Such association was not observed in the II trimester. Iron deficiency was mainly expressed in the third trimester with a strong positive association between TSH and STfR that was also observed in the subgroups with low SF, low $\mathrm{Hb}$, high sTfR and high TSH. sTfR represented the relationship with thyroid status in the I and III trimester. Serum ferritin was positively associated with FT4, and the correlation was statistically significant in the I and III trimester.

The present study enhances our knowledge of iron deficiency during pregnancy and its effect on the maternal thyroid gland function. These findings contribute to the understanding of the dynamics in the serum levels of iron and thyroid status parameters and their relationships in the different periods of pregnancy.

The first limitation of our study is the relatively smaller number of pregnant women in the I trimester of pregnancy compared to the II and III trimester. Another limitation is the lack of information on the pre-pregnancy iron and thyroid status of the participants.

\section{CONCLUSIONS}

The study has demonstrated, for the first time, that the association between iron and thyroid status in pregnant women was changed with progression of pregnancy and it was most prominent in the last trimester. We found that in pregnant women the higher iron requirement (sTfR) related with the increasing maternal blood volume and the iron needs of the fetus correlated with elevated TSH secretion induced by decreased thyroxine. Our results indicate that the combined determination of STfR and TSH is necessary during pregnancy for the assessment of iron deficiency and the risk of hypothyroidism.
Abbreviations
Hb - hemoglobin
SF - serum ferritin
STfR - serum transferrin receptor
FT4 - thyroxine
TSH - thyroid-stimulating hormone

\section{Acknowledgements}

This research was supported by an Intra university research project DP No 6/2012 of Medical University of Plovdiv.

\section{REFERENCES:}

1. Hernik A, Szczepanek-Parulska E, Filipowicz D, Czarnywojtek A, Wrotkowska E, Kramer L, et al. Hepcidin and Iron Homeostasis in $\mathrm{Pa}-$ tients with Subacute Thyroiditis and Healthy Subjects. Mediat Inflamm. 2019 Feb;2019:5764061. [PubMed]

2. Khatiwada S, Gelal B, Baral N, Lamsal M. Association between iron status and thyroid function in Nepalese children. Thyroid Res. 2016 Jan;9:2. [PubMed]
3. Bastian TW, Anderson JA, Fretham SJ, Prohaska JR, Georgieff MK, Anderson GW. Fetal and neonatal iron deficiency reduces thyroid hormone-responsive gene mRNA levels in the neonatal rat hippocampus and cerebral cortex. Endocrinology. 2012 Nov;153(11):5668-80. [PubMed]

4. Zhou M, Liao QK, Li FY, Li Q, Luo $\mathrm{CH}$, Gao J, et al. [Effect of T3 on the expression of transferrin receptor and ferritin in K562 cells and its pos- sible mechanism.] [In Chinese] Zhonghua Xue Ye Xue Za Zhi. 2003 Apr;24(4):181-4. [PubMed]

5. Takamatsu J, Majima M, Miki K, Kuma K, Mozai T. Serum ferritin as a marker of thyroid hormone action on peripheral tissues. J Clin Endocrinol Metab. 1985 Oct;61(4):672-6. [PubMed]

6. Lin $\mathrm{KH}$, Lee $\mathrm{CH}$, Yen $\mathrm{CC}$, Chen SI, Yang RC, Wang CS. Plasma protein regulation by thyroid hormone. $J$ 
Endocrinol. 2003 Dec;179(3):367-77. [PubMed]

7. Fu J, Yang A, Zhao J, Zhu Y, Gu $\mathrm{Y}, \mathrm{Xu}$ Y, et al. The relationship between iron level and thyroid function during the first trimester of pregnancy: A cross-sectional study in Wuxi, China. J Trace Elem Med Biol. 2017 Sept; 43:148-52. [PubMed]

8. Zimmermann MB, Köhrle J. The impact of iron and selenium deficiencies on iodine and thyroid metabolism: biochemistry and relevance to public health. Thyroid. 2002 Oct;12(10):86778. [PubMed]

9. Zimmermann M, Adou P, Torresani T, Zeder C, Hurrell R. Iron supplementation in goitrous, iron-deficient children improves their response to oral iodized oil. Eur J Endocrinol. 2000 Mar;142(3):217-23. [PubMed]

10. Zimmermann MB, Zeder C, Chaouki N, Torresani T, Saad A, Hurrell RF. Addition of microencapsulated iron to iodized salt improves the efficacy of iodine in goitrous, irondeficient children: a randomized, double-blind, controlled trial. Eur $J$ Endocrinol. 2002 Dec; 147(6):747-53. [PubMed]

11. Zimmermann MB. The influence of iron status on iodine utilization and thyroid function. Annu Rev Nutr. 2006; 26:367-89. [PubMed]

12. Zimmermann MB, Wegmueller R, Zeder C, Chaouki N, Rohner F, Saïssi M, et al. Dual fortification of salt with iodine and micronized ferric pyrophosphate: a randomized, doubleblind, controlled trial. Am J Clin Nutr. 2004 Oct;80(4):952-9. [PubMed]

13. Shakir KM, Chute JP, Aprill BS, Lazarus AA. Ferrous sulfate-induced increase in requirement for thyroxine in a patient with primary hypothyroidism. South Med J. 1997 Jun;90(6):637-9. [PubMed]

14. Ravanbod M, Asadipooya K, Kalantarhormozi M, Nabipour I, Omrani GR. Treatment of iron-deficiency anemia in patients with subclinical hypothyroidism. Am J Med. 2013 May;126(5):420-4. [PubMed]

15. Banday TH, Bhat SB, Bhat SB, Bashir S, Naveed S. Incipient iron deficiency in primary hypothyroidism. Thyroid Res Pract. 2018 Nov; 15(3):138-41. [Crossref]

16. Zhang Y, Huang X, Chen Z, Yang Q, Li X, Zhang R, et al. Iron deficiency, a risk factor for thyroid autoimmunity during second trimester of pregnancy in China. Endocr Pract. 2020 Jun;26(6):595-603. [PubMed]

17. Zimmermann MB, Burgi $\mathrm{H}$, Hurrell RF. Iron deficiency predicts poor maternal thyroid status during pregnancy. J Clin Endocrinol Metab. 2007 Sept;92(9):3436-40. [PubMed]

18. Haemoglobin Concentrations for the Diagnosis of Anaemia and Assessment of Severity. World Health Organization. 2011. [Internet]

19. Gatseva PD, Bivolarska AV, Argirova MD. Results from the national strategy for improvement in iodine nutrition in Bulgaria. A study of children and pregnant women living in an iodine-deficient area. J Publ Health. 2011 Apr;19(3):237-40. [Crossref]

20. Bivolarska A, Gatseva P, Maneva A, Deneva T, Porjasov D, Delcheva G. Association between nutritional behaviour and the risk of iron deficiency among pregnant women. Trakia J Sci. 2012;10(1):104-9.

21. Iqbal S, Rust P, Weitensfelder L, Ali I, Kundi M, Moshammer H, et al. Iron and Iodine Status in Pregnant Women from A Developing Country and Its Relation to Pregnancy Outcomes. Int J Environ Res Public Health. 2019 Nov;16(22):4414. [PubMed]

22. Okafor IM, Antai AB, Usanga EA. Evaluation of soluble transferrin receptor, soluble transferrin receptor/ ferritin ratio, and other iron-related parameters of pregnant women in Cross River State, Nigeria. Trop J Med Res. 2017 Jul-Dec;20(2):180-84.

23. Gur EB, Karadeniz M, Inceefe H, Tatar S, Turan GA, Genc M, et al. Thyroid antibodies in euthyroid and subclinical hypothyroidic pregnant women with autoimmune hypothyroidism: effects on hematological parameters and postpartum hemorrhage. Pol Gynaecol. 2015 Apr;86(9):666-71. [PubMed]

24. Tong F, Chen L, Zhao Z. Elevated serum ferritin and soluble transferrin receptor in infants with congenital hypothyroidism. J Pediatr Endocrinol Metab. 2012; 25(3-4):249-53. [PubMed]

Please cite this article as: Delcheva G, Maneva A, Deneva T, Bivolarska A. Association between iron and thyroid status in pregnant women. J of IMAB. 2022 Jan-Mar;28(1):4194-4201. DOI: https://doi.org/10.5272/jimab.2022281.4194

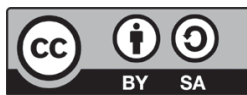

\author{
Address for correspondence: \\ Ginka Delcheva, \\ Department of Medical Biochemistry, Faculty of Pharmacy, Medical Univer- \\ sity of Plovdiv \\ 15A, Vasil Aprilov Blvd., 4002 Plovdiv, Bulgaria \\ E-mail: ginka.delcheva@mu-plovdiv.bg
}

